\title{
Improving the accuracy of pre-operative survival prediction in renal cell carcinoma with C-reactive protein
}

\author{
SPK Jagdev ${ }^{1,7}$, W Gregory ${ }^{2,7}$, NS Vasudev ${ }^{3}$, P Harnden $^{4}$, S Sim $^{1,3}$, D Thompson ${ }^{5}$, J Cartledge ${ }^{6}$, PJ Selby $^{3}$ \\ and RE Banks*,3
}

ISt James's Institute of Oncology, St James's University Hospital, Leeds, UK; ${ }^{2}$ Clinical Trials Research Unit, University of Leeds, Leeds, UK; ${ }^{3}$ Clinical and Biomedical Proteomics Group, Cancer Research UK Centre, Leeds Institute of Molecular Medicine, St James's University Hospital, Leeds LS9 7TF, UK; ${ }^{4}$ Department of Pathology, St James's University Hospital, Leeds, UK; ${ }^{5}$ Department of Clinical Biochemistry and Immunology, St James's University

Hospital, Leeds, UK; ${ }^{6}$ Department of Urology, St James's University Hospital, Leeds, UK

BACKGROUND: Validated objective biomarkers are needed for patients with renal cell carcinoma (RCC) to guide patient management and define high-risk populations for follow-up or for therapeutic purposes.

METHODS: Patients undergoing nephrectomy for RCC ( $n=286$ all stages, $84 \%$ with conventional clear cell type) were included with a median duration follow-up of 5 years. The prognostic significance of pre-operative haematological and biochemical variables, including C-reactive protein (CRP) values were examined and whether they added additional information to a recently published preoperative scoring system was determined.

RESULTS: C-reactive protein was the most significant predictor of overall survival $\left(O S ; \chi^{2}=50.9, P<0.00 \mathrm{I}\right)$. Five-year OS for patients with CRP $\leqslant 15 \mathrm{mg} \mathrm{I}^{-1}$ vs $>\left.15 \mathrm{mg}\right|^{-1}$ was $72 \%(95 \% \mathrm{Cl} 65-78 \%)$ and 33\% (95\% Cl 23-44\%), respectively. Similar results were seen for cancer-specific survival (CSS) and disease-free survival. On multivariate analysis, CRP remained highly significant for CSS $\left(\chi^{2}=17.3, P<0.0001\right)$ and $\mathrm{OS}\left(\chi^{2}=9.8, P<0.002\right)$, in addition to other pre-operative variables including log of neutrophil/ lymphocyte ratio, red blood cell count and white cell count. C-reactive protein was significant in addition to the pre-operative nomogram score $\left(\chi^{2}=12.5, P=0.0004\right.$ for OS, $\chi^{2}=16.2, P=0.0001$ for CSS and $\chi^{2}=8.6, P=0.003$ for DFS) and was still significant when other pre-operative variables were included.

CONCLUSION: C-reactive protein and other haematological and biochemical variables have independent prognostic significance in RCC and may enhance pre-operative scoring systems.

British Journal of Cancer (2010) 103, I649-1656. doi:I0.1038/sj.bjc.6605973 www.bjcancer.com

Published online 9 November 2010

(c) 2010 Cancer Research UK

Keywords: CRP; nomogram; prognosis; pre-operative; RCC

Renal cancer accounts for approximately $3 \%$ of adult malignancies with approximately 210000 cases per year worldwide (GLOBOCAN 2002) (http://www-dep.iarc.fr). Approximately, 70\% of patients have clinically localised disease at presentation, but $20-30 \%$ of these develop metastatic disease after surgery (Bukowski, 2009). Patients are usually followed up with intermittent imaging tests with a multiplicity of regimens proposed (Rouviere et al, 2006). In the curative setting, therefore, there is a need for prognostic markers that can help to stratify patients according to risk, to enable follow-up schedules to be individualised and to tailor eligibility criteria for trials of neo-adjuvant and adjuvant therapies. In the metastatic setting, such factors may help with patient selection for newer targeted therapies to minimise toxicity and maximise resources.

Many prognostic algorithms or models combine elements of the TNM staging system with tumour grade and combinations of pathological or clinical factors (Galfano et al, 2008; Lane and

\footnotetext{
*Correspondence: Professor RE Banks; E-mail: r.banks@leeds.ac.uk

${ }^{7}$ These authors contributed equally to this work.

Revised 5 October 2010; accepted 6 October 2010; published online 9 November 2010
}

Kattan, 2008). However, estimates of risk may be relatively wide for individual patients, not applicable to all subtypes or stages of RCC and some models have not been independently validated. Additionally parameters such as pathological stage and grade are subject to intra- and inter-observer variabilities. More recently, algorithms based on pre-operative variables have been developed. One of these is widely applicable and incorporates age, gender, symptom score, CT-derived size and $\mathrm{T}$ stage and presence or absence of metastatic disease (Karakiewicz et al, 2009). Such models have potential value in determining treatment modality, surgical strategy and neo-adjuvant targeting and patient management pre-operatively.

The area of defining new prognostic markers is of active interest (George and Bukowski, 2007; Crispen et al, 2008). Biomarkers in fluids offer the opportunity for more objective and reproducible measurement before operation. Recent examples include the prognostic significance of pre-operative serum sodium and urinary cathepsin D levels (Vasudev et al, 2008, 2009) and CRP (Ito et al, 2006; Karakiewicz et al, 2007; Komai et al, 2007; Kawata et al, 2008; Lamb et al, 2008; Ramsey et al, 2008; Iimura et al, 2009). In this study we have comprehensively analysed the potential pre-operative prognostic significance of a panel of 
haematological and biochemical variables, including CRP in patients with all stages and histological subtypes of RCC undergoing nephrectomy, and examined their potential utility in combination with a recently published pre-operative (Karakiewicz et al, 2009) scoring system.

\section{PATIENTS AND METHODS}

\section{Patients}

Patients undergoing potentially curative or cytoreductive nephrectomy in Leeds between 1999 and 2006 and who consented to take part were included, excluding patients with familial VHL or polycystic kidney disease. All histological subtypes were included in the analysis (although some separate analyses were also undertaken on patients with clear cell histology only), reflecting the aims of the study in investigating the pre-operative utility of CRP that is, at a time when the histological subtype would be unknown. The study was approved by the Leeds Research Ethics Committee. Clinico-pathological data was largely obtained prospectively with nodal or metastatic disease status determined by CT scan, and all haematological and biochemical variables were measured routinely on pre-operative venous blood samples. C-reactive protein level was measured by a polyethylene glycol (PEG)-enhanced immunoturbidimetric assay on the Siemens Advia 1650 (Siemens Healthcare, Erlangen, Germany).

The pre-operative nomogram score using the variables of gender, age, tumour size and $\mathrm{T}$ stage from imaging and a symptom classification score (Karakiewicz et al, 2009) were calculated for each patient. Patients with T4 disease on CT staging were treated as $\mathrm{T} 3$, as the published nomogram did not include T4.

\section{Statistical methods}

The design and analysis of this retrospective study was conducted according to ReMARK guidelines (McShane et al, 2005). Survival curves were constructed using the life table method, with significance being determined using the log-rank test. Multivariate analysis of survival data used the proportional hazards model with a forward stepwise approach using a $P$-value for inclusion of 0.01 because of the inclusion of so many variables. Harrell's c-index (Harrell et al, 1982) was used to quantify the predictive accuracy of both univariate survival models and multivariate Cox models. This gives a value between $50 \%$, for predictive capacity of the model being no better than random, and $100 \%$ for full predictive capacity. The 12 patients with unknown grades were recoded as grade 3 , as their survival most closely matched that grade. A similar method was used for the few patients who had unknown values for stage or $\mathrm{T}$ stage and for the biochemical/blood variables. This enabled all the patients to be included in the Cox model runs. Additional model runs performed, excluding these patients, demonstrated that this approach was not creating bias. Variables were treated as continuous, or with simple, for example, log transformations in the Cox models, unless analysis using optimum cut-points of the variable gave substantially larger $\chi^{2}$ values in the Cox model. For CRP, a log transformation was most appropriate. The CRP values reported as $<5$ were all assumed to be 2.5 for the purposes of the Cox model analyses. An optimum cut-point was one that maximised the $\chi^{2}$ (or $\beta$ coefficient in the Cox model) from the log-rank test, comparing survival above and below that cut-point. The Cox models were run with and without the pre-operative model scores to determine whether the accuracy of prediction of survival was improved when CRP and other factors were added to it. Correlations of other factors with the log of CRP values were examined using stepwise linear regression with all variables considered as continuous (detailed results not shown). The $r^{2}$ values in the multivariate linear regression indicate how much of the variability in CRP values is explained by the factors included. All $P$-values are two-tailed. Our 1, 2 and 5-year survival figures were compared with those previously published using the preoperative nomogram (Karakiewicz et al, 2009) interpolating between the survival percentages given for different scores in their paper and averaging these over our whole patient population.

Survival was determined based on operation date. DFS was defined from that date until relapse with patients presenting without metastases or with metastases, which were resected being considered as disease free. Patients dying of other causes without relapsing were considered censored for DFS at their date of death.

\section{RESULTS}

The demographics and clinico-pathological characteristics of the 286 patients with CRP values available are shown in Table 1. Median follow-up was 5 years. Analyses, which included treatment and its effects, did not alter the findings and so are not reported.

\section{Univariate analysis of CRP and survival}

C-reactive protein was a highly significant predictor of OS, cancerspecific survival (CSS) and DFS in all RCC histological subtypes examined (Figures 1A-C). Although a log transformation of CRP was used in the Cox model a cut-point of $15 \mathrm{mgl}^{-1}$ was used when depicting survival and DFS differences, as this incorporated much of the effect. The (univariate) predictive capacity of log of CRP, using Harrell's c-index was $70 \%$ for OS, $77 \%$ for CSS and $73 \%$ for DFS. There was no predictive effect of CRP on non-cancer survival (Figure 1D). The survival effect was similar in clear cell and nonclear cell subtypes (Figure 2).

\section{Multivariate (Cox model) analysis}

Univariate and multivariate Cox model results for CSS, OS and DFS are shown in Table 2. C-reactive protein is still highly significantly predictive of survival after inclusion of all the other significant factors for CSS, OS and DFS. Other factors that were independent predictors of CSS on multivariate analysis included tumour stage, grade, WBC, RBC and log of neutrophil/lymphocyte ratio. Log of CRP was the most predictive factor for OS (c-index of $70 \%$ ) and the second most predictive factor after stage for CSS, increasing the predictive capacity from 81 to $86 \%$. On multivariate analysis of factors for OS, the additional independent predictors included the presence of metastases, necrosis, MVI, RBC and WBC. For DFS, the only independent predictors are CRP, age, stage and MVI. C-reactive protein was the second most predictive factor after stage for DFS, increasing the predictive capacity from 77 to $84 \%$.

\section{Landmark analyses pre- and post-1 year}

Cox multivariate analysis of CSS, restricted to deaths within the first year, showed the log of neutrophil/lymphocyte ratio $\left(\chi^{2}=14.5, P=0.0001\right)$ and WBC $\left(\chi^{2}=6.1, P=0.01\right)$ to be significant, plus $\log$ of CRP $\left(\chi^{2}=23.4, P<0.0001\right)$, the presence of metastases $\left(\chi^{2}=12.0, P=0.0005\right), \mathrm{N}$ stage $\left(-\right.$ ve $v s+$ ve, $\chi^{2}=10.6$, $P=0.001)$ and maximum tumour size $(\leqslant 50$ vs $51-100 v s>100$, $\left.\chi^{2}=9.3, P=0.002\right)$. Analysis restricted to patients who had survived more than 1 year showed stage $\left(\chi^{2}=25.2, P<0.0001\right)$, grade $\left(\chi^{2}=9.4, P=0.002\right)$, necrosis $\left(\chi^{2}=6.4, P=0.01\right)$ and sodium $\left(\chi^{2}=8.5, P=0.004\right)$ to be the only relevant factors. C-reactive protein was still highly significant univariately in this latter analysis $\left(\chi^{2}=19.1, P<0.0001\right)$, but was no longer significant multivariately because of its correlations with stage, grade and necrosis. C-reactive protein was significantly correlated with many of the variables analysed (data not shown). 
Table I Characteristics of the 286 renal cancer patients included in the study

\begin{tabular}{|c|c|c|c|c|c|c|c|}
\hline & \multirow[b]{2}{*}{ Characteristics } & \multirow[b]{2}{*}{ n (\%) } & \multirow[b]{2}{*}{ Characteristics } & \multirow[b]{2}{*}{$\begin{array}{c}\text { Median (range) } \\
n(\%) \text { for subsets }\end{array}$} \\
\hline & & & Median (range) & & & & \\
\hline Characteristics & $n(\%)$ & Characteristics & n (\%) for subsets & $\|$ & $28(10)$ & & \\
\hline \multirow{3}{*}{$\begin{array}{l}\text { Age (yrs) } \\
\text { Median } \\
\text { Range }\end{array}$} & & & & III & $90(31)$ & & \\
\hline & 63 & $\mathrm{Hb}(\mathrm{g} \text { per } 100 \mathrm{ml})^{\mathrm{a}}$ & | $3.6(7-20)$ & IV & $58(20)$ & & \\
\hline & $29-86$ & & & Unknown & I (0.3) & $1 / \mathrm{mos}\left(\left.\mathrm{mmol}\right|^{-1}\right)^{\mathrm{a}}$ & $57(2-280)$ \\
\hline \multicolumn{8}{|r|}{ (2) } \\
\hline Male & I 68 (59) & $\mathrm{RBC}\left(\times 10^{12}\right.$ cells per $\left.\mathrm{l}\right)$ & $4.6(2.8-8.0)$ & CT T stage & & & \\
\hline Female & $118(41)$ & $\begin{array}{l}\leqslant 4.25 \\
>4.25 \\
\text { Unknown }\end{array}$ & $\begin{aligned} 70 & (24) \\
215 & (75) \\
1 & (0.3)\end{aligned}$ & $\begin{array}{l}\text { la } \\
\mathrm{lb} \\
2 \\
3\end{array}$ & $\begin{array}{l}75(26) \\
75(26) \\
65(23) \\
43(15)\end{array}$ & $\begin{array}{l}\mathrm{CRP}\left(\left.\mathrm{mg}\right|^{-1}\right) \\
\quad \leqslant 15 \\
>15\end{array}$ & $\begin{array}{l}6.4(<5-266) \\
207(72) \\
79(28)\end{array}$ \\
\hline Histological subtype & & & & 4 & $11(4)$ & & \\
\hline Clear cell & $240(84)$ & WBC $\left(\times 10^{9}\right.$ cells per 1$)$ & $7.7(3.2-17.6)$ & Unknown & $12(6)$ & & \\
\hline Papillary & $25(9)$ & $\leqslant 9.5$ & $229(80)$ & & & & \\
\hline Chromophobe & $12(4)$ & $>9.5$ & $56(20)$ & $C T$ tumour size $(\mathrm{cm})$ & & & \\
\hline Collecting duct & $3(1)$ & & & Range & $2-21$ & & \\
\hline Unclassified & $6(2)$ & & & Unknown & $22(8)$ & & \\
\hline Grade & & & & Symptom score & & & \\
\hline I & $7(2)$ & $\begin{array}{l}\text { Neutrophils } \\
\left(\times 10^{9} \text { cells per } 1\right)\end{array}$ & $5.2(2.25-14.79)$ & $\begin{array}{l}1 \\
2\end{array}$ & $\begin{array}{r}130(45) \\
99(35)\end{array}$ & & \\
\hline 2 & $179(28)$ & $\leqslant 4.9$ & $124(43)$ & 3 & $56(20)$ & & \\
\hline 3 & $117(4 \mid)$ & $>4.9$ & $160(56)$ & Unknown & I (0.3) & & \\
\hline 4 & $72(25)$ & Unknown & $2(1)$ & & & & \\
\hline
\end{tabular}

Table I (Continued)
$2(1)$

$1.7(0.26-7.35)$

$37(13)$

$248(87)$

I (0.3)

$\begin{array}{lcl}\begin{array}{l}\text { Necrosis } \\ \text { Present }\end{array} & 94(33) & \begin{array}{l}\text { Monocytes } \\ \left(\times 10^{9} \text { cells per I) }\right.\end{array} \\ \text { Absent } & 183(64) & \text { Unknown } \\ \text { Unknown } & 9(3) & \end{array}$

MVI

Present
Absent

Unknown

$\begin{array}{cc}\text { II } 8 \text { (4I) } & \text { Neuts/Lymphs } \\ \text { I64 (57) } & \text { Unknown } \\ & \text { Mean } \\ 4(1) & \text { Mean log }\end{array}$

pT stage

।

2

3

4

Unknown

$N$ stage

0

$$
\begin{aligned}
117(4 \mid) & \begin{array}{l}
\text { Platelets } \\
\left(\times 10^{9}\right. \text { cells per I) }
\end{array} \\
35(12) & 0-360 \\
131(46) & 36 \mid-884 \\
2(1) & \text { Unknown } \\
\text { I (0.3) } &
\end{aligned}
$$

25 I (88) Sodium $\left(\mathrm{mmol}^{-1}\right)$

$$
35(12)
$$

\begin{tabular}{|c|c|c|c|}
\hline \\
\hline 0 & $228(80)$ & Potassium $\left(\mathrm{mmol}^{-1}\right)$ & $4.4(3.1-6.0)$ \\
\hline I & $58(20)$ & $\begin{array}{l}\leqslant 4.3 \\
>4.3 \\
\text { Unknown }\end{array}$ & $\begin{array}{c}126(44) \\
154(54) \\
6(2)\end{array}$ \\
\hline
\end{tabular}

$127-138$
$139-147$
Unknown
Mean

$140(127-147)$

$95(33)$

$190(66)$

I (0.3)

139.5

\section{TNM stage}

109 (38) Creatinine $\left.(\mu \mathrm{mol})^{-1}\right)^{\mathrm{b}}$
Abbreviations: $\mathrm{CRP}=\mathrm{C}$-reactive protein; $\mathrm{CT}=$ computed tomography; $\mathrm{Hb}=$ haemoglobin; $\mathrm{K}=$ potassium; Lymphs = lymphocytes; $\mathrm{M}=$ metastasis; monos = monocytes; $\mathrm{MVI}$, microvascular invasion; $\mathrm{N}=$ nodal; $\mathrm{Na}=$ sodium; Neuts = neutrophils; $\mathrm{RBC}=$ red blood cells; $\mathrm{T}=$ tumour, $\mathrm{WBC}=$ white blood cell count. Reference ranges are: $\mathrm{Hb}$ level, female: $11.5-16.0 \mathrm{~g}$ per $100 \mathrm{ml}$, male: $\mid 3.5-18.0 \mathrm{~g}$ per $100 \mathrm{ml}$; WBC, $4.0-11.0 \times 10^{9}$ cells per I; RBC, $3.8-5.8 \times 10^{12}$ cells per l; neutrophil count, $2.00-7.5 \times 10^{9}$ cells per I; monocyte count, $0.2-0.8 \times 10^{9}$ cells per I, platelets count, $150-400 \times 10^{9}$ cells per I; sodium level, $135-145 \mathrm{mmol}^{-1}$; potassium level, $3.5-5.0 \mathrm{mmol}^{-1}$; creatinine level, female: $70-\left.100 \mu_{\text {mol }}\right|^{-1}$, male: $80-1 \mid 5 \mu$ mol ${ }^{-1}$; urea

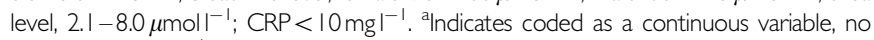
obvious cut-points. 'Indicates coded as a log transformation, again no obvious cut-points.

\section{Pre-operative prognostic variables}

Pre-operative nomogram score gave excellent separation of the CSS, OS and DFS curves with similar survival estimates to the original published nomogram estimates (Karakiewicz et al, 2009) (Figure 3A). The predictive accuracy of this nomogram on our data, using Harrell's c-index, was $74 \%$ (compared with $86 \%$ for the data on which it was validated (Karakiewicz et al, 2007)). The slight early survival advantage in our series appeared to derive predominantly from the patients with higher nomogram scores, and therefore poorer prognosis.

In Cox model analysis, CRP is significant in addition to the nomogram score $\left(\chi^{2}=12.5, \quad P=0.0004\right.$ for OS, $\chi^{2}=16.2$, $P=0.0001$ for CSS and $\chi^{2}=8.6, P=0.003$ for DFS), although the increase in predictive accuracy, as measured by Harrell's c-index, was uniformly only about $2 \%$. However, to take OS as an example, predicted survival curves from the Cox model for CRP below and above 15 , are still widely separated (Figure $3 \mathrm{~B}$ ), corresponding to the $2 \%$ improvement in predictive accuracy after allowing for nomogram score, with an individual having CRP $\leqslant 15$ having an $86 \%$ 5-year survival compared with $69 \%$ for a patient with CRP $>15$ even after allowing for the nomogram score. Including the other significant pre-operative variables from Table 2, CRP was still significant for $\operatorname{OS}\left(\chi^{2}=7.8, \quad P=0.005\right), \operatorname{CSS}\left(\chi^{2}=13.6\right.$, $P=0.0002)$ and DFS $\left(\chi^{2}=11.2, P=0.0008\right)$. The nomogram score was not as predictive as the other pre-operative factors from Table 2 (CRP, metastases, RBC and WBC) for OS and does not provide extra prognostic information for survival in addition to these variables. 
A
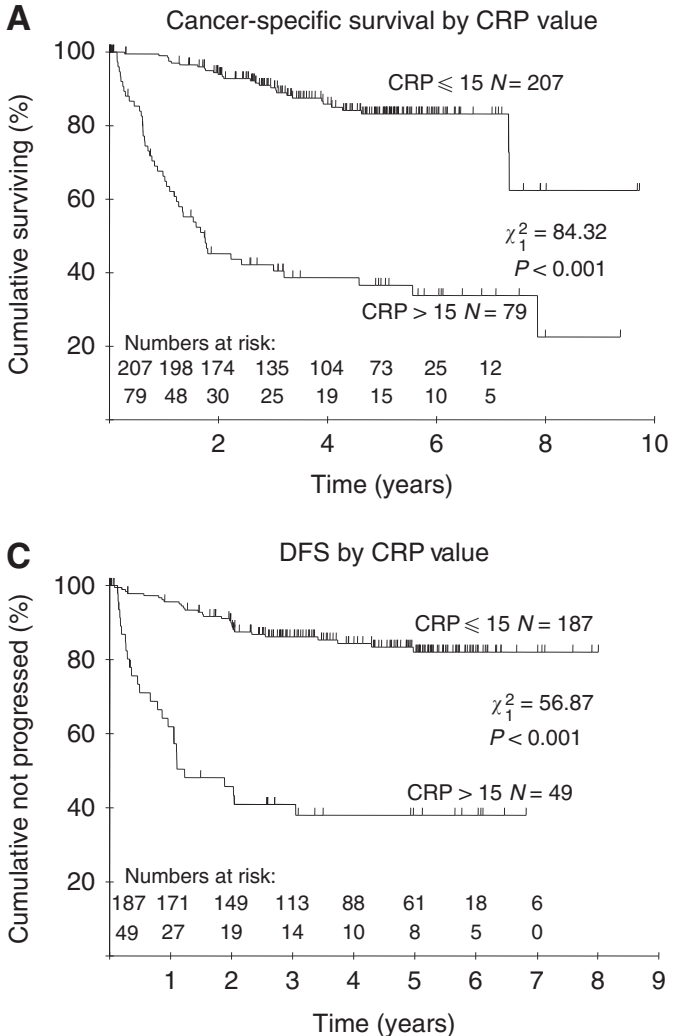

B

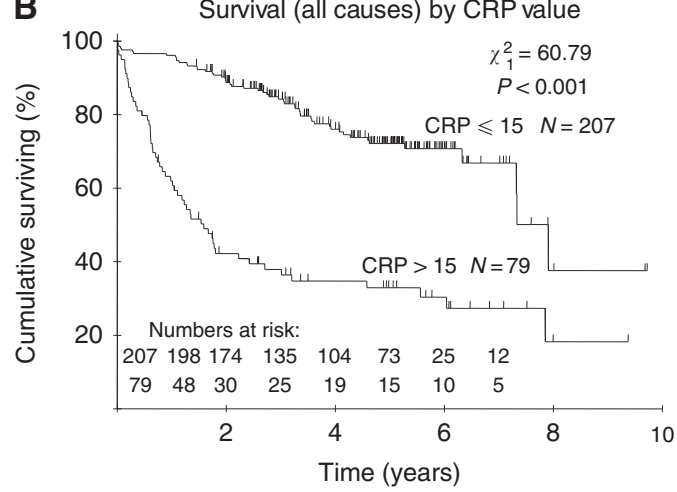

D

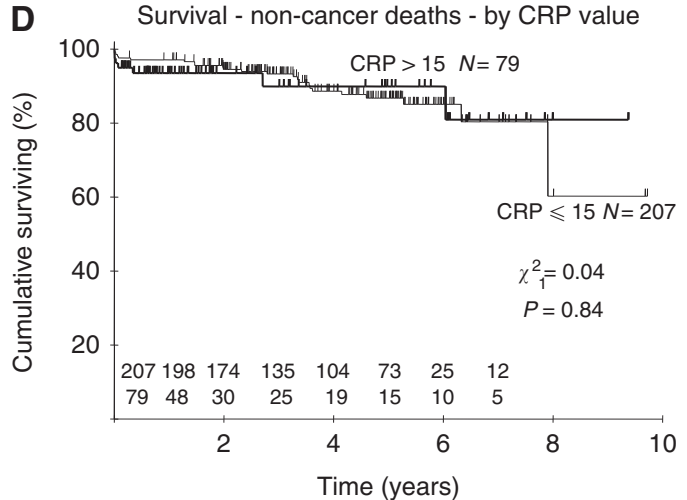

Figure I Kaplan-Meier survival curves demonstrating the effect of CRP in relation to (A) CSS, (B) OS, (C) DFS and (D) non-cancer-related survival in patients undergoing nephrectomy for RCC. The 5-year OS was $72 \%$ (95\% Cl 65-78\%) for patients with a CRP $\leqslant$ I 5 mg I I $^{-1}$ and 33\% (95\% Cl 23-44\%) for patients with a CRP > $15 \mathrm{mgl}^{-1}$ with corresponding 3-year OS being $84 \%$ (95\% Cl 78-89\%) and 38\% (95\% Cl 28-49\%). The 5-year CSS was $83 \%$ (95\% Cl $76-88 \%)$ for patients with a CRP $\leqslant 15 \mathrm{mgl}^{-1}$ and $37 \%(95 \% \mathrm{Cl} 26-49 \%)$ for patients with a CRP $>15 \mathrm{mg} \mathrm{I}^{-1}$ and corresponding 3-year CSS figures were $90 \%$ (95\% Cl 85-94\%) and 42\% (95\% Cl 32-54\%). The 5-year DFS was $82 \%$ (95\% Cl $75-87 \%)$ for patients with a CRP $\leqslant 15 \mathrm{mgl}{ }^{-1}$ and $38 \%(95 \% \mathrm{Cl}$ $25-53 \%)$ for patients with a CRP> $15 \mathrm{mgl}^{-1}$ with corresponding 3-year DFS being $86 \%(95 \% \mathrm{Cl} 80-90 \%)$ and $41 \%(95 \% \mathrm{Cl} 28-56 \%)$, respectively.

CSS - clear cell and non-clear cell (broken lines) by CRP value

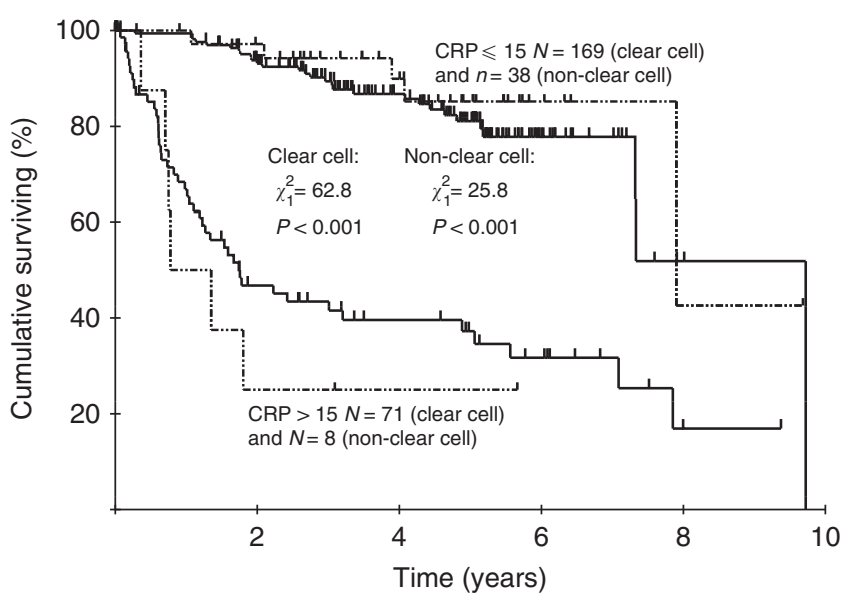

Figure 2 Kaplan-Meier survival curves demonstrating the effect of CRP in relation to CSS for clear cell histology (---) and non-clear cell histology in patients undergoing nephrectomy for RCC.

Log of CRP was correlated with nomogram score $(r=0.50$, $P<0.001$ ), and this changed only imperceptibly when CRP was analysed as a categorical variable above and below $15(r=0.53$,
$P<0.001)$. C-reactive protein appeared to provide most additional explanatory power in the lower nomogram score ranges, although the numbers became small. For CSS, there was an effect in the $<100$ range, with 3 out of 104 deaths in the low CRP group and 2 out of 10 in the high CRP group $\left(\chi^{2}=10.7, P=0.001\right)$. For DFS, $\mathrm{CRP}$ again gave additional prognostic information in the good nomogram score categories $\left(<100\right.$ : low CRP $v$ s high CRP $\chi^{2}=7.3$, $P=0.007$ and $\left.100-150: \chi^{2}=5.7, P=0.02\right)$.

\section{DISCUSSION}

Previous studies have reported the independent prognostic significance of CRP measured before nephrectomy in patients with RCC in studies ranging from 40 to 313 patients (Jabs et al, 2005; Ito et al, 2006; Karakiewicz et al, 2007; Komai et al, 2007; Kawata et al, 2008; Lamb et al, 2008; Ramsey et al, 2008; Iimura et al, 2009). We confirm these, but importantly our study involving 286 patients is the first to include all stages, histological subtypes and all of CSS, OS and DFS, hence broadening the applicability. Although the comparison of CRP with scoring systems, such as the Kattan, UISS and SSIGN scores, has been made (Karakiewicz et al, 2007; Ramsey et al, 2008), we also show for the first time the independence of CRP and several other biochemical and haematological variables compared with a recently proposed preoperative prognostic algorithm. This may indicate a potential contribution to such models, which may allow the more accurate stratification of individuals for treatment and monitoring. Preoperatively, this could be of importance in determining patient 
Table 2 Cox model predictors of (a) CSS, (b) OS and (c) DFS.

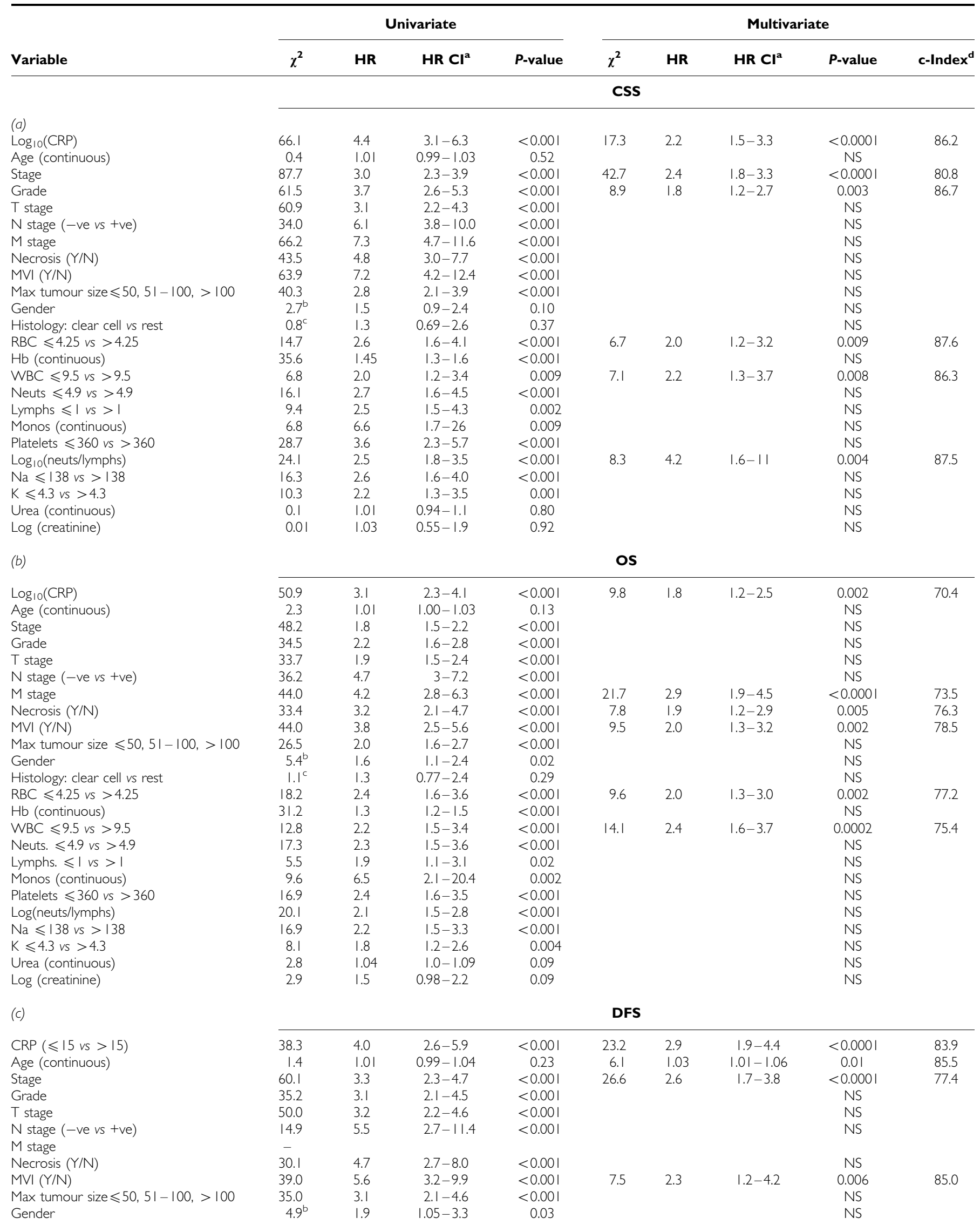


Table 2 (Continued)

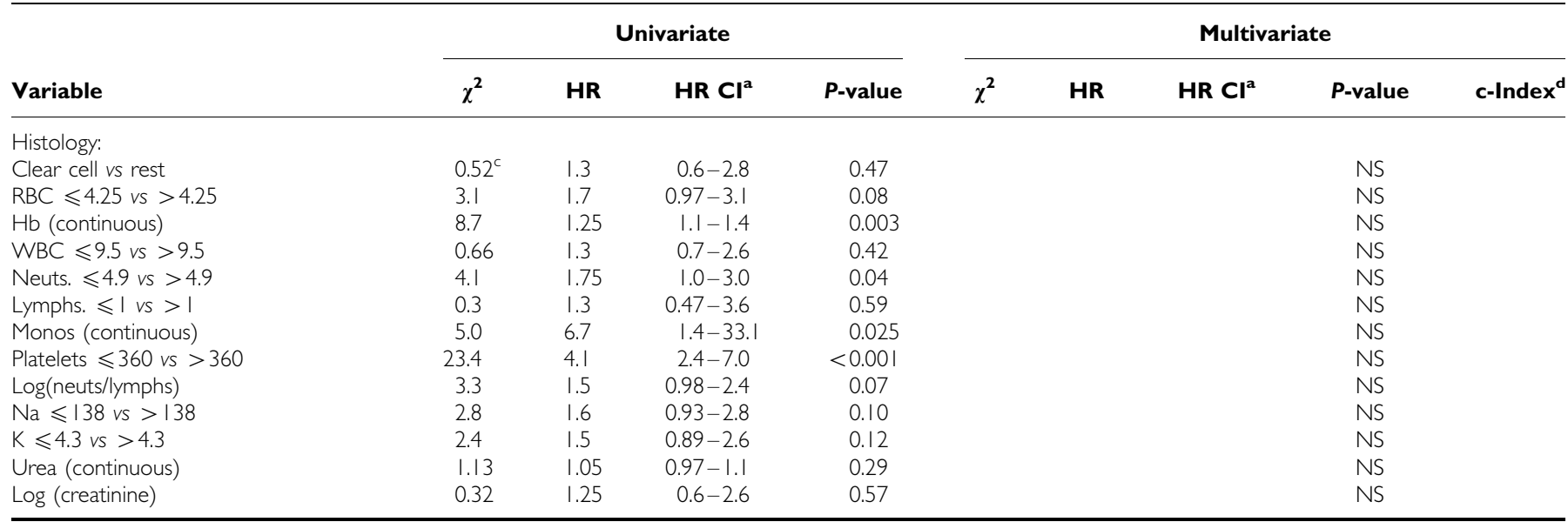

Abbreviations: $\mathrm{Cl}=$ confidence interval; $\mathrm{CSS}=$ cancer-specific survival; DFS = disease-free survival; $\mathrm{HR}=$ hazard ratio; NS = not significant; OS, overall survival. Units in table 2 are similar to those shown in table I. ${ }^{a} 95 \%$ confidence interval. ${ }^{b}$ Worse survival in male patients. ${ }^{c}$ Clear cell with worse survival. ${ }^{\text {do }}$ at inclusion of variable.

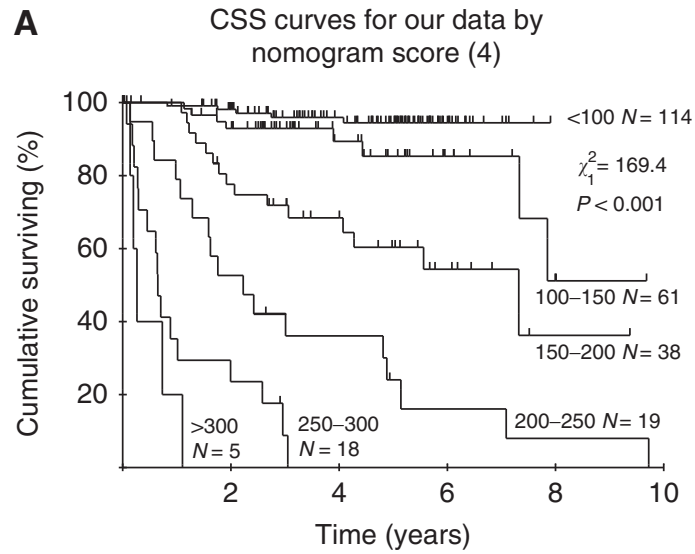

B Estimated survival curves from Cox model for a patient with mean nomogram score by CRP value

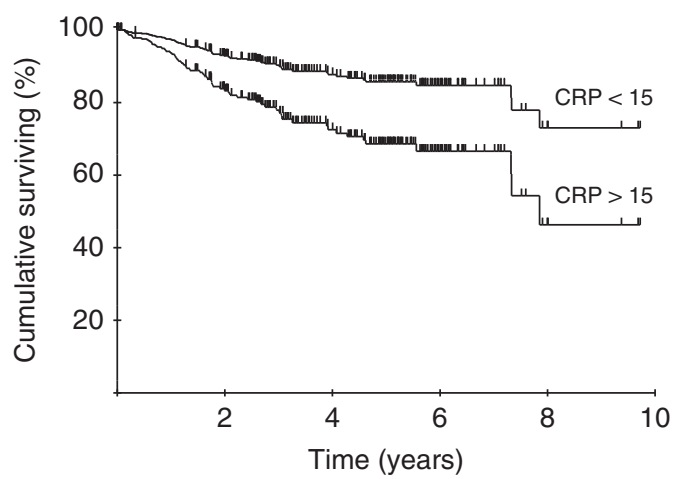

Figure 3 (A) Survival (CSS) curves for our data by nomogram score (Karakiewicz et al, 2009). The I-, 2- and 5-year estimates for our data (published nomogram data) (Karakiewicz et al, 2009) are 91.9 (87.5\%), 83.0 (80.2\%) and 72.4\% (73.9\%), respectively. (B) Cox model predicted survival curves for a patient having the mean nomogram score and CRP below and above 15, demonstrating the additional effect of CRP in predicting survival beyond the nomogram score effect in patients undergoing nephrectomy for RCC.

treatment, such as selection of higher-risk patients, given the advent of neo-adjuvant therapies, or in the case of advanced disease those who most warrant cytoreductive nephrectomy with its inherent risks. Conversely, in a post-operative setting, higher risk patients may be identified for adjuvant therapies and/or monitored more intensively, all of which have implications for health economics and patient quality of life.

C-reactive protein is also associated with prognosis of other tumour types and recently in a study involving 10408 individuals observed over 16 years as part of the Copenhagen City Heart Study; baseline levels of CRP were associated with increased risk of developing cancer (Allin et al, 2009). Importantly, this study used a high-sensitivity assay for CRP, allowing examination of values at a higher level of resolution within the 'normal' interval. Further analysis of CRP in two pooled prospective cohorts from the British Women's Heart and Health study and the Caerphilly cohort and a meta-analysis also found an association with cancer risk (Heikkila et al, 2009).

A criticism made in using CRP as a prognostic indicator is its perceived low specificity owing to its being an acute-phase reactant produced by the liver in a variety of inflammatory or infectious diseases. However, highly significant discrimination between RCC patients with poor and good outcome was possible, and encouragingly CRP was not associated with non-cancer death in our study. The use of repeated baseline measurements (Ledue and Rifai, 2003; Pearson et al, 2003) may allow the impact of subclinical or clinical acute inflammatory illnesses to be determined. However, there is evidence in RCC that CRP is produced by normal and malignant renal epithelial cells (Jabs et al, 2003, 2005) with a significant correlation between pre-operative serum CRP and tissue CRP mRNA levels.

On multivariate analysis CRP clearly provides additional information to the pre-operative model (Karakiewicz et al, 2009). The small increase in predictive accuracy of about $2 \%$, using Harrell's c-index, is not unexpected in such multivariate analyses. Schemper and Henderson, (2000) state that 'the likely amount of predictive accuracy is often low even if there are highly significant and relatively strong prognostic factors'. They recommend graphical comparisons of survival curves and clearly the CRP curves corresponding to the $2 \%$ improvement in predictive accuracy are still widely separated even after allowing for the nomogram score. This additional separation is interesting given that one component of the nomogram is symptom scores, which CRP may be expected to partly reflect. Our data shows that CRP is 
highly correlated with many factors but in the multivariate linear regression the overall $r^{2}$ value for log of CRP only reached $49 \%$ and so $51 \%$ of the variability in CRP values is unexplained by factors examined. This variable is, therefore, also measuring an independent effect of some nature, and therefore has the potential to predict effects of a previously unknown nature. Its objective measurement and correlation with the other factors such as stage, MVI, necrosis and TNM augurs well for its use as a monitoring variable, as it is obviously related to other factors that are clearly relevant, although not completely assessable before treatment.

In addition to CRP, several other routinely measured biochemical and haematological parameters were shown to have independent prognostic significance, including log of neutrophil/ lymphocyte ratio, serum sodium and WBC. Importantly these provided additional information to the pre-operative score (Karakiewicz et al, 2009) in this study. This is in contrast to a previous smaller study (Ramsey et al, 2008) in which on multivariate analysis apart from clinico-pathological variables and the SSIGN, UISS and Kattan scores, only CRP but not other haematological variables was significant for CSS or RFS. This difference is most likely because of the more heterogeneous cohort in our study, as when the patients with metastatic disease were excluded, the neutrophil/lymphocyte ratio was then no longer independently significant. Our model therefore has identified other parameters that could be of value in an integrated scoring system. This is the first report of the neutrophil/lymphocyte ratio as an independent predictive factor of survival in RCC patients, although previously described in other cancers such as ovarian cancer (Cho et al, 2009).

The concept of using additional measurable biomarkers together with clinico-pathological scoring systems is so far restricted to tissue with promising markers, including p53, vimentin and CAIX (Kim et al, 2004) or Ki-67, p53, endothelial/epithelial VEGFR1 and epithelial VEGF-D (Klatte et al, 2009). C-reactive protein is even more attractive being a routinely, relatively inexpensive and objectively measured analyte available pre-operatively. The additional value of this and other routinely measured biochemical and haematological variables with pre-operative nomograms such as that proposed by Karakiewicz et al (2009) should now be explored further prospectively in a larger series of patients. Such studies should include consideration of any known potential confounding factors such as BMI, smoking or HRT (Ledue and Rifai, 2003; Heikkila et al, 2007) and the role of co-morbidities and environmental factors in influencing an individual's baseline value as exemplified in cardiovascular disease (Ruckerl et al, 2009) in which high-sensitivity CRP measurements are currently used in risk assessment (Pearson et al, 2003).

\section{ACKNOWLEDGEMENTS}

We thank the Cancer Research, UK for financial support and the patients and hospital staff who participated in this research.

\section{REFERENCES}

Allin KH, Bojesen SE, Nordestgaard BG (2009) Baseline C-reactive protein is associated with incident cancer and survival in patients with cancer. $J$ Clin Oncol 27: 2217-2224

Bukowski RM (2009) Prognostic factors for survival in metastatic renal cell carcinoma: update 2008. Cancer 115(10 Suppl): 2273-2281

Cho H, Hur HW, Kim SW, Kim SH, Kim JH, Kim YT, Lee K (2009) Pretreatment neutrophil to lymphocyte ratio is elevated in epithelial ovarian cancer and predicts survival after treatment. Cancer Immunol Immunother 58: $15-23$

Crispen PL, Boorjian SA, Lohse CM, Leibovich BC, Kwon ED (2008) Predicting disease progression after nephrectomy for localized renal cell carcinoma: the utility of prognostic models and molecular biomarkers. Cancer 113: 450 - 460

Galfano A, Novara G, Iafrate M, Cavalleri S, Martignoni G, Gardiman M, D'Elia C, Patard JJ, Artibani W, Ficarra V (2008) Mathematical models for prognostic prediction in patients with renal cell carcinoma. Urol Int 80: $113-123$

George S, Bukowski RM (2007) Biomarkers in clear cell renal cell carcinoma. Expert Rev Anticancer Ther 7: 1737-1747

Harrell FE, Califf RM, Pryor DB, Lee KL, Rosati RA (1982) Evaluating the yield of medical tests. JAMA 247: 2543-2546

Heikkila K, Ebrahim S, Lawlor DA (2007) A systematic review of the association between circulating concentrations of $\mathrm{C}$ reactive protein and cancer. J Epidemiol Community Health 61: 824-832

Heikkila K, Harris R, Lowe G, Rumley A, Yarnell J, Gallacher J, Ben-Shlomo Y, Ebrahim S, Lawlor DA (2009) Associations of circulating C-reactive protein and interleukin- 6 with cancer risk: findings from two prospective cohorts and a meta-analysis. Cancer Causes Control 20: 15-26

Iimura Y, Saito K, Fujii Y, Kumagai J, Kawakami S, Komai Y, Yonese J, Fukui I, Kihara K (2009) Development and external validation of a new outcome prediction model for patients with clear cell renal cell carcinoma treated with nephrectomy based on pre-operative serum C-reactive protein and TNM classification: the TNM-C score. I Urol 181: $1004-1012$

Ito K, Asano T, Yoshii H, Satoh A, Sumitomo M, Hayakawa M (2006) Impact of thrombocytosis and C-reactive protein elevation on the prognosis for patients with renal cell carcinoma. Int J Urol 13: 1365 - 1370

Jabs WJ, Busse M, Kruger S, Jocham D, Steinhoff J, Doehn C (2005) Expression of C-reactive protein by renal cell carcinomas and unaffected surrounding renal tissue. Kidney Int 68: 2103-2110
Jabs WJ, Logering BA, Gerke P, Kreft B, Wolber EM, Klinger MH, Fricke L, Steinhoff J (2003) The kidney is a second site of human C-reactive protein formation in vivo. Eur I Immunol 33: 152-161

Karakiewicz PI, Hutterer GC, Trinh QD, Jeldres C, Perrotte P, Gallina A, Tostain J, Patard JJ (2007) C-reactive protein is an informative predictor of renal cell carcinoma-specific mortality: a European study of 313 patients. Cancer 110: $1241-1247$

Karakiewicz PI, Suardi N, Capitanio U, Jeldres C, Ficarra V, Cindolo L, De La Taille A, Tostain J, Mulders PFA, Bensalah K, Artibani W, Salomon L, Zigeuner R, Valeri A, Descotes J-L, Rambeaud J-J, Mejean A, Montorsi F, Bertini R, Patard J-J (2009) A preoperative prognostic model for patients treated with nephrectomy for renal cell carcinoma. Eur Uro 55: 287-295

Kawata N, Nagane Y, Yamaguchi K, Ichinose T, Hirakata H, Takahashi S (2008) How do symptoms have an impact on the prognosis of renal cell carcinoma. Int J Urol 15: 299-303

Kim HL, Seligson D, Liu X, Janzen N, Bui MH, Yu H, Shi T, Figlin RA, Horvath S, Belldegrun AS (2004) Using protein expressions to predict survival in clear cell renal carcinoma. Clin Cancer Res 10(16): $5464-5471$

Klatte T, Seligson DB, LaRochelle J, Shuch B, Said JW, Riggs SB, Zomorodian N, Kabbinavar FF, Pantuck AJ, Belldegrun AS (2009) Molecular signatures of localized clear cell renal cell carcinoma to predict disease-free survival after nephrectomy. Cancer Epidemiol Biomarkers Prev 18: 894-900

Komai Y, Saito K, Sakai K, Morimoto S (2007) Increased preoperative serum C-reactive protein level predicts a poor prognosis in patients with localized renal cell carcinoma. BJU Int 99: 77-80

Lamb GWA, McArdle PA, Ramsey S, McNichol A-M, Edwards J, Aitchison M, McMillan DC (2008) The relationship between the local and systemic inflammatory responses and survival in patients undergoing resection for localized renal cancer. $B r$ J Urol 102: $756-762$

Lane BR, Kattan MW (2008) Prognostic models and algorithms in renal cell carcinoma. Urol Clin North Am 35: 613-625

Ledue TB, Rifai N (2003) Preanalytic and analytic sources of variations in C-reactive protein measurement: implications for cardiovascular disease risk assessment. Clin Chem 49: 1258-1271

McShane LM, Altman DG, Sauerbrei W, Taube SE, Gion M, Clark GM (2005) Reporting recommendations for tumor marker prognostic studies (REMARK). J Natl Cancer Inst 97(16): 1180-1184

Pearson TA, Mensah GA, Alexander RW, Anderson JL, Cannon RO, Criqui M, Fadl YY, Fortmann SP, Hong Y, Myers GL, Rifai N, Smith SC, Taubert K, 
Tracy RP, Vinicor F (2003) Markers of inflammation and cardiovascular disease: application to clinical and public health practice. A statement for healthcare professionals from the Centers for Disease Control and Prevention and the American Heart Association. Circulation 107: 499-511

Ramsey S, Lamb GWA, Aitchison M, McMillan DC (2008) Prospective study of the relationship between the systemic inflammatory response, prognostic scoring systems and relapse-free and cancer-specific survival in patients undergoing potentially curative resection for renal cancer. Br J Urol 101: 959-963

Rouviere O, Bouvier R, Negrier S, Badet L, Lyonnet D (2006) Nonmetastatic renal-cell carcinoma: is it really possible to define rational guidelines for post-treatment follow-up? Nat Clin Pract Oncol 3(4): 200-213

Ruckerl R, Peters A, Khuseyinova N, Andreani M, Koenig W, Meisinger C, Dimakopoulou K, Sunyer J, Lanki T, Nyberg F, Schneider A (2009) Determinants of the acute-phase response protein C-reactive protein in myocardial infarction survivors: the role of co-morbidities and environmental factors. Clin Chem 55: 322-335
Schemper M, Henderson R (2000) Predictive accuracy and explained variation in Cox regression. Biometrics 56: 249-255

Vasudev NS, Brown JE, Brown SR, Rafiq R, Morgan R, Patel PM, O’Donnell D, Harnden P, Rogers M, Cocks K, Anderson K, Paul A, Eardley I, Selby PJ, Banks RE (2008) Prognostic factors in renal cell carcinoma: asopciation of preoperative sodium concentration with survival. Clin Cancer Res 14: $1775-1781$

Vasudev NS, Sim S, Cairns DA, Feguson RE, Craven RA, Stanley A, Cartledge J, Thompson D, Selby PJ, Banks RE (2009) Pre-operative urinary cathepsin $\mathrm{D}$ is associated with survival in patients with renal cell carcinoma. Br J Cancer 101: 1175-1182

cc)(-) (2) This work is licensed under the Creative BY NG SA Commons Attribution-NonCommercial-Share Alike 3.0 Unported License. To view a copy of this license, visit http://creativecommons.org/licenses/by-nc-sa/3.0/ 